\title{
Erratum to: The stabilizing potential of anterior, posterior and combined techniques for the reconstruction of a 2-level cervical corpectomy model: biomechanical study and first results of ATPS prototyping
}

Heiko Koller • Rene Schmidt • Michael Mayer •

Wolfgang Hitzl · Juliane Zenner · Stefan Midderhoff •

Nicolaus Graf • H. Resch $\cdot$ Hans-Joachim Wilke

Published online: 20 April 2011

(C) Springer-Verlag 2011

Erratum to: Eur Spine J (2010) 19:2137-2148

DOI 10.1007/s00586-010-1503-x

The names of the co-authors Wilke, Graf, and Midderhoff were rendered incorrectly; they are corrected here.

The online version of the original article can be found under doi:10.1007/s00586-010-1503-x.

H. Koller · M. Mayer · H. Resch

Department for Traumatology and Sport Injuries,

Paracelsus Medical University, Salzburg, Austria

H. Koller $(\bowtie) \cdot$ J. Zenner

German Scoliosis Center, Werner-Wicker-Clinic,

Bad Wildungen, Germany

e-mail: heiko.koller@t-online.de

R. Schmidt

Department of Orthopedics and Traumatology,

University Medical Center, Mannheim, Germany

W. Hitzl

Research Office, Department of Biostatistics,

Paracelsus Medical University, Salzburg, Austria

S. Midderhoff · N. Graf · H.-J. Wilke

Department of Orthopedic Research and Biomechanics,

University of Ulm, Ulm, Germany 